\title{
Performance Evaluation of Newly Developed Korean Antimicrobial Susceptibility Testing Panels for MicroScan System Using Clinical Isolates from Teaching Hospitals in Korea
}

\author{
Da Young Kang, ${ }^{1,2}$, Jun Sung Hong', Byeol Yi Park ${ }^{1,2}$, In-Ho Jang², \\ Dokyun Kim', Hyukmin Lee ${ }^{1}$, Seok Hoon Jeong ${ }^{1}$ \\ ${ }^{1}$ Department of Laboratory Medicine and Research Institute of Bacterial Resistance, \\ Yonsei University College of Medicine, Seoul, \\ ${ }^{2}$ Department of Clinical Pathology, Sangji University College of Health Science, Wonju, Korea
}

Background: Antimicrobial resistant continues to pose a threat to public health. Therefore, rapid and accurate antimicrobial susceptibility testing is very important. The objectives of this study were to evaluate the performance of the MicroScan system (Beckman Coulter, USA) with newly developed Korean Antimicrobial Susceptibility Testing Panels (KSCM panels) for antimicrobial susceptibility testing (AST) against clinical isolates in South Korea.

Methods: Three KSCM panels were designed in this study. For the performance evaluation, a total of 1,325 clinical isolates including 1,027 of Gram-negative bacilli and 298 Gram-positive cocci collected from eight general hospitals in South Korea were used. The results by KSCM panels were compared with those by conventional methods.

Results: By KSCM-1 panel for Gram-positive cocci, the rates of categorical agreement (CA) were $>90 \%$ in all the antimicrobials tested in this study. The rates of major error (ME) were also $<3 \%$, and only three very major error (VME) were identified; each of ampicillin, tetracycline, and quinupristin-dalfopristin in enterococcal isolates. By KSCM-2 panel for Enterobacteriaceae, the rates of CA were also above $90 \%$, and those of ME and VME were less than $3 \%$ and $1.5 \%$, respectively. KSCM-3 panels for glucose-non-fermenting Gram-negative bacilli, also showed good agreement rates, i.e., CA rates $>90 \%$, ME rates $<3 \%$, and VME rates $<1.5 \%$.

Conclusion: The newly developed three KSCM panels for MicroScan system (Beckman Coulter) showed excellent performance in AST against a large number of clinical isolates, and they are applicable to clinical microbiology laboratories. (Ann Clin Microbiol 2019;22:61-70)

Key Words: Antimicrobial susceptibility, Evaluation, MicroScan, Performance

\section{INTRODUCTION}

주요 병원균의 항균제 내성은 다양한 공중보건 문제를 유발 하는 전세계적인 위협이 되고 있다. 그람양성균에서는 methicillin 내성 Staphylcoccus aureus (methicillin-resistant S. aureus, MRSA)와 vancomycin 내성 장알균(vancomycin- resistant enterococci, VRE) 등이 지속적으로 문제가 되고 있고, 그람음성균 에서는 extended-spectrum $\beta$-lactamase (ESBL) 생성 장내세균
등이 널리 확산되어 있다[1-3]. 최근에는 carbapenem 내성 장내 세균(carbapenem-resistant Enterobacteriaceae, CRE), carbapenem 내성 Pseudomonas aeruginosa (carbapenem-resistant $P$. aeruginosa, CRPA) 및 carbapenem 내성 Acinetobacter baumannii (carbapenem-resistant A. baumannii, CRAB)가 널리 확 산되어 공중보건에 큰 위협이 되고 있다[4-6]. 다제내성균의 확 산을 방지하기 위해 많은 노력이 이루어졌으나, 다제내성균은 꾸준히 증가하여, 2016년 국내 종합병원 다제내성균 조사 사업

Received 28 December, 2018, Revised 22 April, 2019, Accepted 3 May, 2019

Correspondence: Dokyun Kim, Department of Laboratory Medicine and Research Institute of Bacterial Resistance, Gangnam Severance Hospital, Yonsei University College of Medicine, 211 Eonju-ro, Gangnam-gu, Seoul 06273, Korea. (Tel) 82-2-2019-2776, (Fax) 82-2-2057-8926, (E-mail) kyunsky@yuhs.ac

(c) The Korean Society of Clinical Microbiology.

(ㄷ) This is an Open Access article distributed under the terms of the Creative Commons Attribution Non-Commercial License (http://creativecommons.org/licenses/by-nc/4.0) which permits unrestricted non-commercial use, distribution, and reproduction in any medium, provided the original work is properly cited. 
(Korean Global Antimicrobial Surveillance System, Kor-GLASS)의 결과에 따르면 MRSA는 $61 \%$, VRE는 $34 \%$, cefotaxime 내성 Escherichia coli는 35\%였으며, 특히 carbapenem 내성 Klebsiella pneumoniae는 약 1\%, CRPA는 33\%, 그리고 $\mathrm{CRAB}$ 는 $83 \%$ 였다[7].

다제내성균에 의한 감염은 나쁜 예후와 연관성이 있는 것으 로 알려져 있으며, 분리된 병인균에 대한 빠르고 정확한 항균 제 감수성 검사가 적절한 항균제 치료에 매우 중요하다[8]. 항 균제 감수성 시험은 한천희석법, 미량액체배지희석법 등의 희 석법이 표준 검사법으로 제시되어 있으나, 많은 양의 균주를 단시간에 처리하기 어렵고 검사인력이 많이 요구되는 특성이 있어 임상미생물 검사실에 적용하기는 어렵다. 따라서, 대부분 의 임상미생물 검사실에서는 자동화 장비를 이용하여 항균제 감수성 검사가 시행된다. 자동화 장비를 이용한 항균제 감수성 시험은 많은 양의 균주를 비교적 단시간 내에 검사하고, 표준 검사법인 미량액체배지희석법을 기초로 하여 진행된다는 장점 이 있으나, 항균제 감수성 패널에 포함되어 있는 항균제만 검 사가 가능하다는 단점이 있다. Clinical Laboratory Standard Institute (CLSI)와 European Committee on Antimicrobial Susceptibility Testing (EUCAST)은 매년 각 균종별로 대상 항균제 를 재정립하여 발표하고 있으나, 현재 시판 중인 항균제 감수 성 검사 패널은 이를 반영하지 못한 경우가 많으며, 국내 사정 이 고려되지 않은 경우가 많다. 다제내성 그람양성균의 치료를 위한 새로운 항균제인 ceftaroline, tedizolid와 다제내성 그람음 성균 치료의 새로운 항균제인 ceftazidime-avibactam, ceftolozane-tazobactam 등이 포함되어 있지 않으며, Salmonella 균속 의 fluoroquinolone 계열 항균제의 감수성 판정범위가 포함되어 있지 않다. 또한 검사 대상 항균제는 국가별, 지역별 항균제 내 성률 및 임상의의 선호도에 맞추어 결정되어야 하므로, 국내 실정에 맞는 항균제 감수성 검사 패널이 필요하다.

MicroScan (Beckman Coulter, Brea, CA, USA)은 균종 동정 및 항균제 감수성 시험을 시행하는 자동화 장비로서 VITEK system (bioMérieux, Marcy l'Étoile, France)과 함께 국내에서 가장 널리 사용되고 있는 장비 중 하나이다. MicroScan (Beckman Coulter)은 미량액체배지희석법을 기초로 하고 있으 며, 정해진 배양시간 이후 균의 성장을 종료점으로 결과를 제 시하므로, 균의 성장곡선을 분석하는 VITEK system (bioMérieux)보다 처리시간이 길다는 단점이 있으나, 표준검사 법과 방법적 유사성이 크다는 장점이 있다. 본 연구에서는 MicroScan (Beckman Coulter)의 3가지 항균제 감수성 패널, 즉, 그람양성균 패널(KSCM-1), 그람음성 장내세균 패널 (KSCM-2), 그리고 포도당 비발효 그람음성균 패널(KSCM-3) 을 구성하였다. 각 패널의 항균제 조합은 CLSI M100-S28의 test group A와 B를 포함할 수 있도록 하였으며, 임상의들이 선 호하는 항균제 및 새로이 가이드라인에 추가된 신약을 포함하
도록 하였다[9,10]. 또한 새로 고안된 3가지 패널에 대하여 임 상 분리균주를 이용하여 검사능을 평가하였다.

\section{MATERIALS AND METHODS}

\section{MicroScan KSCM 패널의 구성}

KSCM-1 패널에는 임상에서 가능 흔히 분리되는 병인균인 Staphylococcus 균종과 Enterococcus 균종의 test group A 항균 제인 penicillin, ampicillin, oxacillin, erythromycin, clindamycin 및 trimethoprim-sulfamethoxazole을 포함하였으며, test group B 항균제인 vancomycin, daptomycin, linezolid, ceftaroline, tetracycline, minocycline 및 rifampin을 포함하였다. 또한, test group investigational이지만, 국내 임상의들의 선호가 높은 teicoplanin을 포함하였다[11,12]. 추가적으로, MRSA 검출능을 높 이기 위하여 cefoxitin 선별시험 well을 포함하였다. Enterococcus 의 혈류감염 치료 시 사용되는 aminoglycoside의 상승효과와 연관된 gentamicin과 streptomycin 고도내성 검출 well을 추가 하였으며, enterococci의 요로감염의 치료에 사용되는 test group $\mathrm{U}$ 항균제인 tetracycline, ciprofloxacin, levofloxacin 및 nitrofurantoin 또한 포함하였다.

KSCM-2에는 test group A 항균제인 ampicillin, cefazolin, gentamicin 및 tobramycin을 포함하였다. Test group B 항균제 중에서 국내에서 가장 흔하게 검출되는 CTX-M형 ESBL 생성 여부를 판단할 수 있는 3세대 cephalosporin인 cefotaxime과 4 세대 cephalosporin인 cefepime 및 cephamycin 계열인 cefoxitin 을 포함하였으며, 그람음성균 요로감염에서 가장 흔히 사용되 는 fluoroquinolone 계열의 항균제인 ciprofloxacin, levofloxacin 과 moxifloxacin을 포함하였다. Carbapenem 내성 검출을 위한 ertapenem, meropenem 및 imipenem, 그리고 carbapenem-producing Enterobacteriaceae (CPE)의 치료에 이용되는 colistin을 추가하였다. 마지막으로, 국내에서는 아직 사용할 수 없지만, 최근 $\mathrm{CPE}$ 의 치료를 위해 출시된 신약인 ceftazidime-avibactam 과 ceftolozane-tazobactam을 패널에 추가하였다.

$\mathrm{KSCM}-3$ 에는 CLSI 및 EUCAST 가이드라인의 권고사항에 따라, 임상에서 주로 많이 분리되는 병인균인 Pseudomonas 균 종과 Acinetobacter 균종의 test group A 항균제인 piperacillin, ceftazidime, gentamicin, tobramycin 및 ampicillin-sulbactam을 포함하였으며, test group $\mathrm{B}$ 항균제인 ticarcillin, piperacillin-tazobactam, cefepime, aztreonam, doripenem, imipenem, meropenem, amikacin, ciprofloxacin, levofloxacin, ticarcillinclavulanate, cefotaxime, ceftriaxone, tetracycline, doxycycline, minocycline 및 trimethoprim-sulfamethoxazole을 포함하였다. 추 가적으로, 요로감염의 치료에 사용되는 test group U 항균제인 norfloxacin도 포함하였다. 또한, carbapenem 내성균주의 치료에 사용이 증가하고 있는 항균제인 colistin을 추가하였고, carbape- 
nem 내성 균주 치료를 위해 출시된 새로운 항균제인 ceftolozane-tazobactam과 ceftazidime-avibactam을 패널에 추가하였다.

\section{2. 대상 균주}

2016년 5월에서 2017년 4월까지 전국 8개의 병원에서 수집 된 혈액 분리 균주를 이용하여 검사능에 대한 평가를 진행하였 다. 같은 환자에서 균이 반복 분리된 경우 첫 번째 분리된 균주 를 이용하였다. 대상 균주는 혈액한천배지에 계대배양한 후 순 수 분리된 집락을 검사를 시행할 때까지 $-70^{\circ} \mathrm{C}$ 에 보관하였다.

그람양성균은 총 298주였으며, S. aureus가 100주, Enterococcus faecium 이 100주, Enterococcus faecalis 가 98주였다. 그 람음성균은 총 902주였으며, 그 중 Enterobacteriaceae는 691 주, 포도당비발효 그람음성균이 211주였다. Enterobacteriaceae 에는 E. coli 226주, K. pneumonia 330주, Klebsiella oxytoca 1 주, Salmonella 균속 111주, Enterobacter 균속 23주가 포함되었 으며, 포도당 비발효 그람음성균에는 P. aeruginosa가 114주, A. baumannii는 97주가 포함되었다. 추가적으로 colistin에 대한 검사능을 평가하기 위해 $m c r-1$ 양성 colistin 내성 균주 18주, $m c r-1$ 음성 colistin 내성 균주 73주 및 colistin 감수성 균주 34 주를 포함하였다.

\section{3. 균종 동정}

균종 동정은 말디토프 질량분석기(matrix-assisted laser desorption/ionization time-of-flight mass spectrometer, MALDITOF MS)인 Bruker Biotyper (Bruker, Billerica, MA, USA)를 사용하였다. 혈액 한천 배지에 두 차례 계대배양하여 얻은 단 일 균집락을 플레이트에 얇게 도말하고, 매트릭스 용액 $1 \mu \mathrm{L}$ 를 분주하여 완전히 건조시킨 후에 장비로 분석하였다. 얻어진 미생물의 단백질 스펙트럼을 데이터베이스와 비교 분석하여 균종을 동정하며, 동정 점수가 2.0 이상이 되었을 때 균종을 확 정하였다. 동정 점수가 2.0 미만인 경우 $16 \mathrm{~S} \mathrm{rRNA}$ 유전자의 염 기서열 분석을 시행하여 그 결과를 EzBIO Cloud 데이터베이스 (https://www.ezbiocloud.net/)와 비교하여 균종을 확정하였다.

\section{KSCM 패널을 이용한 항균제 감수성 시험}

MicroScan KSCM 패널(Beckman Coulter)을 이용한 항균제 감수성 시험은 제조사가 제시한 방법을 따랐다. 균종을 두 차 례 혈액 한천 배지에 계대배양한 후 얻은 단일 집락을 무균 상 태의 $3 \mathrm{~mL}$ 접종수에 $0.08-0.10 \mathrm{McFarland}(\mathrm{McF})$ 의 농도로 맞 추었다. 만들어진 균액의 $100 \mu \mathrm{L}$ 을 $25 \mathrm{~mL}$ 의 접종수 (inoculum water)에 분주하여 표준균액을 만든 후 Renok inoculator (Beckman Coulter)를 이용하여 패널의 96 well에 115 $\mu \mathrm{L}$ 씩 고르게 분주하였다. 표준 균액을 접종한 패널은 $37^{\circ} \mathrm{C}$ 배양기에서 16-18시간 동안 배양하였으며, 배양 후 각 well에 서 균의 성장을 육안으로 판독하여 최소억제농도를 측정하였
다. 균액 준비 과정 및 접종은 15 분 내에 진행되었으며, 무균 상태를 유지하도록 하였다.

\section{5. 표준방법의 항균제 감수성 시험}

1) 그람 양성균: S. aureus의 경우 cefoxitin, erythromycin, clindamycin, quinupristin-dalfopristin, trimethoprim-sulfamethoxazole 및 고농도 mupirocin에 대하여 디스크확산법으로 억제대 크기를 측정하였다. 또한 vancomycin, teicoplanin과 linezolid는 E-test를 통해 최소억제농도(minimal inhibitory concentration)를 측정하였다. 장알균 중 E. faecium은 ampicillin, ciprofloxacin, tetracycline, quinupristin-dalfopristin에 대하여 디스크확산법을 이용하여 억제대 크기를 측정하였으며, 고농도 gentamicin, 고 농도 streptomycin의 내성은 CLSI 및 EUCAST 가이드라인에 따라 디스크확산법과 미량액체배지희석법을 이용하여 판단하 였다 $[9,10]$. 추가적으로 vancomycin, teicoplanin과 linezolid에 대하여 E-test로 최소억제농도를 측정하였다. E. faecalis의 경 우 E. faecium 과 동일한 방법으로 감수성 시험을 진행하였으며, penicillin에 대한 감수성 시험(디스크 확산법)을 추가적으로 시 행하였으며, 자연내성인 quinupristin-dalfopristin은 대상 항균제 에서 제외하였다. 디스크확산법으로 측정된 억제대의 크기와 E-test 및 미량액체배지희석법으로 측정된 최소억제농도를 CLSI M100-S28 및 EUCAST의 clinical breakpoint에 따라 감수 성/중등도내성/내성을 구분하였다[9,10].

2) Enterobacteriaceae: Enterobacteriaceae의 경우 ampicillin, piperacillin, ampicillin-sulbactam, cefazolin, cefotaxime, ceftazidime, cefepime, aztreonam, cefoxitin, amikacin, gentamicin, trimethoprim-sulfamethoxazole, tigecycline 및 ertapenem에 대하 여 디스크 확산법을 이용하여 억제대의 크기를 측정하였다. 또 한, imipenem과 meropenem의 최소억제농도는 Mueller-Hinton $(\mathrm{MH})$ 한천배지(Difco Laboratories, Detroit, MI, US)를 이용하 여 한천희석법(측정범위: $0.5-256 \mathrm{mg} / \mathrm{L}$ )으로 측정하였으며, $E$. coli ATCC 25922와 P. aeruginosa ATCC 27853을 표준균주로 이용하였다. 0.5 McF 탁도를 맞춘 균부유액 $1 \mu \mathrm{L}$ 를 Steers replicator 등을 이용하여 $\mathrm{MH}$ 배지 표면에 접종하였고, $37^{\circ} \mathrm{C}$ 배 양기에서 16-24시간 배양하여 최소억제농도를 판단하였다[13]. Colistin의 최소억제농도는 CLSI-EUCAST Polymyxin Breakpoints Working Group의 권고에 따라 미량액체배지희석 법(측정범위: $0.5-16 \mathrm{mg} / \mathrm{L}$ )으로 측정하였다[14]. 미량액체배지 희석법의 결과 판정은 검사자에 의한 오차를 방지하기 위해 두 사람의 관찰자가 맹검으로 실시하였고, 일치하지 않은 경우 두 관찰자가 다시 동시에 확인하여 최종적으로 결정하였다. Salmonella 균속은 cefotaxime, ceftazidime, ciprofloxacin 및 imipenem을 대상으로 미량액체배지희석법을 통해 최소억제농 도를 측정하였다.

3) 포도당 비발효 그람음성균: P. aeruginosa의 경우 piper- 
acillin, piperacillin-tazobactam, ceftazidime, cefepime, imipenem, meropenem, amikacin, gentamicin, tobramycin 및 ciprofloxacin에 대하여 디스크확산법으로 억제대 크기를 측정하였 다. A. baumannii는 piperacillin, ampicillin-sulbactam, ceftazidime, cefepime, imipenem, meropenem, amikacin, gentamicin, tobramycin, ciprofloxacin 및 minocycline으로 디스크확산법을 이용하여 항균제 감수성 검사를 시행하였다.

\section{6. 결과 분석}

각 항균제별로 categorical agreement (CA), essential agreement (EA), very major error (VME), major error (ME) 그리고 minor error $(\mathrm{mE})$ 의 비율을 측정하였다[15]. CA는 MicroScan (Beckman Coulter)과 표준방법의 감수성, 중등도 내성, 내성의 결과가 서로 일치한 것으로 하였다. 최소억제농도를 측정한 경 우에는 2 배 이내의 희석범위 내 일치를 EA로 정의하였다. 두 가지 방법 중 하나에서만 중등도 내성, 다른 방법에서는 내성 혹은 감수성 결과인 경우를 $\mathrm{mE}$ 로 판정하였다. 표준방법에서 내성인 결과가 평가방법에서 감수성으로 나온 경우를 $\mathrm{VME}$ 라 고 하였고, 반대로 표준방법에서 감수성인 결과가 평가방법에 서 내성으로 나온 경우 $\mathrm{ME}$ 라고 판정하였다.

\section{RESULTS}

\section{KSCM-1 패널과 표준검사법에 의한 항균제 감수성 결과 비교}

$\mathrm{KSCM}-1$ 패널과 표준검사법에 의한 항균제 감수성 결과의 항균제별 분포를 Supplementary Fig. 1, 2와 Table 1에 정리하 였다. S. aureus에서 디스크확산법으로 검사한 항균제인 cefoxitin, erythromycin, clindamycin, quinupristin-dalfopristin, trimethoprim-sulfamethoxazole, mupirocin에서 $\mathrm{CA}$ 의 비율이 $95.0 \%$ (범위: $95.0 \%-100 \%$ ) 이상으로 비교적 높은 일치율을 나타내었 다. $\mathrm{ME}$ 는 고농도 mupirocin 내성 검출에서 4\% (4/100)로 다소 높았으나, 그 외에 항균제에서는 관찰되지 않았다. 또한 $\mathrm{VME}$ 역시 모든 항균제에서 관찰되지 않았다. E-test로 검사한 항균 제인 vancomycin, teicoplanin 및 linezolid에서 $\mathrm{CA}$ 의 비율은 각 각 $100 \%(n=100), 100 \%(n=100)$ 및 $99.0 \%(n=99), E A$ 의 비율 은 각각 $95 \%(\mathrm{n}=95), 91 \%(\mathrm{n}=91), 99 \%(\mathrm{n}=99)$ 였다. Vancomycin 과 teicoplanin에서는 $\mathrm{ME}$ 또는 $\mathrm{VME}$ 가 관찰되지 않았으며, linezolid에서 1건의 $\mathrm{VME}$ 를 확인하였다.

Enterococci에서는 ampicillin, penicillin, ciprofloxacin, tetracycline, quinupristin-dalfopristin 및 aminoglycoside 항균제인 gentamicin과 streptomycin에 대한 감수성 시험을 디스크확산법 을 시행하였다. 그 결과, ciprofloxacin에서 $88.4 \%$ (175/198), 고

Table 1. The results of KSCM-1 panel comparing with conventional methods

\begin{tabular}{|c|c|c|c|c|c|c|}
\hline \multirow{2}{*}{ Antibiotics } & \multirow{2}{*}{$\begin{array}{c}\text { Conventional } \\
\text { method }\end{array}$} & \multicolumn{5}{|c|}{ Results of KSCM-1 panel comparing with conventional method number $(\%)$} \\
\hline & & $\mathrm{CA}$ & EA & $\mathrm{mE}$ & $\mathrm{ME}$ & VME \\
\hline \multicolumn{7}{|l|}{ Staphylococcus aureus } \\
\hline Cefoxitin & DD & $100(100)$ & - & $0(0)$ & $0(0)$ & $0(0)$ \\
\hline Erythromycin & $\mathrm{DD}$ & $97(97.0)$ & - & $3(3.0)$ & $0(0)$ & $0(0)$ \\
\hline Clindamycin & DD & $95(95.0)$ & - & $5(5.0)$ & $0(0)$ & $0(0)$ \\
\hline Quinupristin-dalfopristin & DD & $100(100)$ & - & $0(0)$ & $0(0)$ & $0(0)$ \\
\hline Trimethoprime-sulfamethoxazole & DD & $100(100)$ & - & - & $0(0)$ & $0(0)$ \\
\hline High-level mupirocin & DD & $96(96.0)$ & - & - & $4(4.0)$ & $0(0)$ \\
\hline Vancomycin & E-test & $100(100)$ & $95(95.0)$ & $0(0)$ & $0(0)$ & $0(0)$ \\
\hline Teicoplanin & E-test & $100(100)$ & $91(91.0)$ & $0(0)$ & $0(0)$ & $0(0)$ \\
\hline Linezolid & E-test & $99(99.0)$ & $99(99.0)$ & $0(0)$ & $0(0)$ & $1(1.0)$ \\
\hline \multicolumn{7}{|l|}{ Enterococcus species } \\
\hline Ampicillin & $\mathrm{DD}$ & $195(98.5)$ & - & $0(0)$ & $2(1.0)$ & $1(0.5)$ \\
\hline Penicillin & DD & $98(100)$ & - & $0(0)$ & $0(0)$ & $0(0)$ \\
\hline Ciprofloxacin & DD & $175(88.4)$ & - & $22(11.1)$ & $1(0.5)$ & $0(0)$ \\
\hline High-level gentamicin & $\mathrm{DD}$ & $158(79.8)$ & - & $22(11.1)$ & $18(9.1)$ & $0(0)$ \\
\hline High-level streptomycin & $\mathrm{DD}$ & $168(84.8)$ & - & $20(10.1)$ & $10(5.1)$ & $0(0)$ \\
\hline Tetracycline & DD & $193(97.5)$ & - & $2(1.0)$ & $2(1.0)$ & $1(0.5)$ \\
\hline Quinupristin-dalfopristin & DD & $90(90.0)$ & - & $8(8.0)$ & $1(1.0)$ & $1(1.0)$ \\
\hline Vancomycin & E-test & $195(98.5)$ & $194(98.0)$ & $0(0)$ & $3(1.5)$ & $0(0)$ \\
\hline Teicoplanin & E-test & $191(96.5)$ & $194(98.0)$ & $6(3.0)$ & $0(0)$ & $1(0.5)$ \\
\hline Linezolid & E-test & $190(96.0)$ & $190(96.0)$ & $7(3.5)$ & $0(0)$ & $1(0.5)$ \\
\hline
\end{tabular}

Abbreviations: CA, categorical agreement; EA, essential agreement; mE, minor error; ME, major error; VME, very major error; DD, disk diffusion method. 
농도 gentamicin에서 $79.8 \%(\mathrm{n}=158)$, 고농도 streptomycin에서 $84.8 \%(\mathrm{n}=168)$ 로 다소 낮은 일치율을 보였으나, 이를 제외한 대부분의 항균제에서 $\mathrm{CA}$ 의 비율은 $90 \%$ (88.4\%-100\%) 이상으 로 우수한 일치율을 보였다. ME는 penicillin에서는 관찰되지 않았고, 고농도 gentamicin $(9.1 \%, \mathrm{n}=18)$, 고농도 streptomycin $(5.1 \%, \mathrm{n}=10$ )를 제외한 나머지 항균제들도 $3 \%$ (범위: $0.5 \%-1.5 \%)$ 이하로 우수한 결과를 나타냈다. Ampicillin, tetracycline과 quinupristin-dalfopristin에서 각각 1 건의 $\mathrm{VME}$ 를 확인 하였고, 나머지 항균제에서는 VME가 관찰되지 않았다. E-test 로 검사한 항균제인 vancomycin, teicoplanin 및 linezolid에서 $\mathrm{CA}$ 의 비율은 각각 $98.5 \%(\mathrm{n}=195), 96.5 \% \quad(\mathrm{n}=191), 96.0 \%$ $(\mathrm{n}=190), \mathrm{EA}$ 의 비율은 각각 $98 \%(\mathrm{n}=194), 98 \%(\mathrm{n}=194), 96 \%$ $(n=190)$ 였다. Teicoplanin과 linezolid에서 1건의 VME를 확인 하였고, vancomycin에서 3건의 $\mathrm{ME}$ 를 확인하였다.

\section{KSCM-2 패널과 표준검사법에 의한 항균제 감수성 결과 비교}

Enterobacteriaceae의 KSCM-2 패널 검사 결과와 표준검사 법에 의한 항균제 감수성 결과의 항균제별 분포를 Supplementary Fig. 3과 Table 2에 정리하였다. 디스크확산법으로 검사한 항균제인 ampicillin, piperacillin, ampicillin-sulbactam, cefazo- lin, cefotaxime, ceftazidime, cefepime, aztreonam, cefoxitin, amikacin, gentamicin, trimethoprim-sulfamethoxazole, tigecycline 및 ertapenem에서 $\mathrm{CA}$ 의 비율이 $90 \%$ (범위: $90.1 \%-96.6 \%$ ) 이상이었다. $\mathrm{ME}$ 의 비율은 검사한 모든 항균제에서 $3 \%$ 미만으 로 우수한 일치율을 보여주었으나, trimethoprim-sulfamethoxazole에서 2.9\% (17/593)로 다소 높았다. VME의 비율은 모두 $1.5 \%(0.2 \%-1 \%)$ 이하였다. 한천희석법으로 검사한 항균제인 imipenem과 meropenem은 CA의 비율이 각각 $93.8 \%(182 / 194)$, 97.0\% ( $\mathrm{n}=188)$ 였으며, $\mathrm{EA}$ 의 비율은 $95.9 \%(\mathrm{n}=186), 93.8 \%$ $(\mathrm{n}=182)$ 였다. Imipenem은 ME와 VME의 비율 모두 $0.5 \%(\mathrm{n}=1)$ 였고, meropenem은 $\mathrm{ME}$ 와 $\mathrm{VME}$ 의 비율 모두 $1 \%(\mathrm{n}=2)$ 였다.

Salmonella의 KSCM-2 패널과 미량액체배지희석법에 의한 항균제 감수성 결과의 항균제별 분포는 Supplementary Fig. 4 와 Table 2에 정리하였다. 미량액체배지희석법으로 검사한 항 균제인 cefotaxime, ceftazidime, ciprofloxacin 및 imipenem에서 $\mathrm{CA}$ 의 비율은 각각 $99.1 \%(110 / 111), 95.5 \%(\mathrm{n}=106), 100 \%$ $(\mathrm{n}=111), 100 \%(\mathrm{n}=111)$ 였고, $\mathrm{EA}$ 의 비율은 각각 $99.1 \%(\mathrm{n}=110)$, 99.1\% $(\mathrm{n}=110), 95.5 \%(\mathrm{n}=106), 100 \%(\mathrm{n}=111)$ 로 높은 일치율 을 나타내었다. Cefotaxime, ceftazidime에서 1건의 $\mathrm{ME}$ 를 확인 하였고, $\mathrm{VME}$ 는 검사한 모든 항균제에서 관찰되지 않았다.

Table 2. The results of KSCM-2 panel comparing with conventional methods

\begin{tabular}{|c|c|c|c|c|c|c|}
\hline \multirow{2}{*}{ Antibiotics } & \multirow{2}{*}{$\begin{array}{l}\text { Conventional } \\
\text { method }\end{array}$} & \multicolumn{5}{|c|}{ Results of KSCM-2 panel comparing with conventional method number (\%) } \\
\hline & & $\mathrm{CA}$ & EA & $\mathrm{mE}$ & ME & VME \\
\hline \multicolumn{7}{|l|}{ Enterobacteriaceae } \\
\hline Ampicillin & DD & $472(95.5)$ & - & $10(2.0)$ & $8(1.6)$ & $4(0.8)$ \\
\hline Piperacillin & DD & $551(92.9)$ & - & $35(5.9)$ & $2(0.3)$ & $5(0.8)$ \\
\hline Ampicillin-sulbactam & DD & $534(90.1)$ & - & $47(7.9)$ & $8(1.3)$ & $4(0.7)$ \\
\hline Cefazolin & DD & $537(90.6)$ & - & $45(7.6)$ & $3(0.5)$ & $6(1.0)$ \\
\hline Cefotaxime & DD & $573(96.6)$ & - & $12(2.0)$ & $3(0.5)$ & $5(0.8)$ \\
\hline Ceftazidime & DD & $549(92.6)$ & - & $60(5.0)$ & $11(1.9)$ & $3(0.5)$ \\
\hline Cefepime & DD & $538(90.7)$ & - & $49(8.3)$ & $4(0.7)$ & $2(0.3)$ \\
\hline Aztreonam & DD & $556(93.8)$ & - & $24(2.0)$ & $12(2)$ & $1(0.2)$ \\
\hline Cefoxitin & DD & $537(90.6)$ & - & $40(6.7)$ & $11(1.9)$ & $5(0.8)$ \\
\hline Amikacin & DD & $559(94.3)$ & - & $24(4.0)$ & $7(1.2)$ & $3(0.5)$ \\
\hline Gentamicin & DD & $566(95.4)$ & - & $10(1.7)$ & $11(1.9)$ & $6(1.0)$ \\
\hline Trimethoprim-sulfamethoxazole & DD & $547(92.2)$ & - & $26(4.4)$ & $17(2.9)$ & $3(0.5)$ \\
\hline Tigecycline & DD & $542(91.4)$ & - & $47(8.0)$ & $3(0.5)$ & $1(0.2)$ \\
\hline Ertapenem & DD & $544(91.7)$ & - & $38(6.4)$ & $9(1.5)$ & $2(0.3)$ \\
\hline Imipenem & Agar dilution & $182(93.8)$ & $186(95.9)$ & $9(4.6)$ & $1(0.5)$ & $1(0.5)$ \\
\hline Meropenem & Agar dilution & $188(97.0)$ & $182(93.8)$ & $2(1.0)$ & $2(1.0)$ & $2(1.0)$ \\
\hline Colistin & BMD & $118(94.4)$ & $118(94.4)$ & $0(0)$ & $6(4.8)$ & $1(0.8)$ \\
\hline \multicolumn{7}{|l|}{ Salmonella } \\
\hline Cefotaxime & BMD & $110(99.1)$ & $110(99.1)$ & $0(0)$ & $1(0.9)$ & $0(0)$ \\
\hline Ceftazidime & BMD & $106(95.5)$ & $110(99.1)$ & $4(3.6)$ & $1(0.9)$ & $0(0)$ \\
\hline Ciprofloxacin & $\mathrm{BMD}$ & $111(100)$ & $106(95.5)$ & $0(0)$ & $0(0)$ & $0(0)$ \\
\hline Imipenem & BMD & $111(100)$ & $111(100)$ & $0(0)$ & $0(0)$ & $0(0)$ \\
\hline
\end{tabular}

Abbreviations: CA, categorical agreement; EA, essential agreement; $\mathrm{mE}$, minor error; ME, major error; VME, very major error; DD, disk diffusion method; BMD, broth microdilution. 
Table 3. The results of KSCM-3 panel comparing with conventional methods

\begin{tabular}{|c|c|c|c|c|c|}
\hline \multirow{2}{*}{ Antibiotics } & \multirow{2}{*}{$\begin{array}{c}\text { Conventional } \\
\text { method }\end{array}$} & \multicolumn{4}{|c|}{ Results of KSCM-3 panel comparing with conventional method number (\%) } \\
\hline & & $\mathrm{CA}$ & $\mathrm{mE}$ & ME & VME \\
\hline \multicolumn{6}{|l|}{ Pseudomonas aeruginosa } \\
\hline Piperacillin & DD & $101(91.8)$ & $9(8.2)$ & $0(0)$ & $0(0)$ \\
\hline Piperacillin-tazobactam & DD & $103(93.6)$ & $7(6.4)$ & $0(0)$ & $0(0)$ \\
\hline Ceftazidime & DD & $104(94.6)$ & $5(4.5)$ & $1(0.9)$ & $0(0)$ \\
\hline Cefepime & DD & $103(93.6)$ & $6(5.5)$ & $0(0)$ & $1(0.9)$ \\
\hline Imipenem & DD & $103(93.6)$ & $7(6.4)$ & $0(0)$ & $0(0)$ \\
\hline Meropenem & DD & $108(98.2)$ & $2(1.8)$ & $0(0)$ & $0(0)$ \\
\hline Amikacin & DD & $109(99.1)$ & $0(0)$ & $0(0)$ & $1(0.9)$ \\
\hline Gentamicin & DD & $106(96.4)$ & $4(3.6)$ & $0(0)$ & $0(0)$ \\
\hline Tobramycin & DD & $110(100)$ & $0(0)$ & $0(0)$ & $0(0)$ \\
\hline Ciprofloxacin & DD & $109(99.1)$ & $0(0)$ & $1(0.9)$ & $0(0)$ \\
\hline \multicolumn{6}{|l|}{ Acinetobacter baumannii } \\
\hline Piperacillin & DD & $84(95.5)$ & $3(3.4)$ & $0(0)$ & $1(1.1)$ \\
\hline Ampicillin-sulbactam & DD & $82(93.2)$ & $6(6.8)$ & $0(0)$ & $0(0)$ \\
\hline Ceftazidime & DD & $86(97.7)$ & $2(2.3)$ & $0(0)$ & $0(0)$ \\
\hline Cefepime & DD & $86(97.7)$ & $2(2.3)$ & $0(0)$ & $0(0)$ \\
\hline Imipenem & DD & 88 (100) & $0(0)$ & $0(0)$ & $0(0)$ \\
\hline Meropenem & DD & 88 (100) & $0(0)$ & $0(0)$ & $0(0)$ \\
\hline Amikacin & DD & 86 (97.7) & $2(2.3)$ & $0(0)$ & $0(0)$ \\
\hline Gentamicin & DD & 77 (87.5) & $11(12.5)$ & $0(0)$ & $0(0)$ \\
\hline Tobramycin & DD & 87 (98.9) & $1(1.1)$ & $0(0)$ & $0(0)$ \\
\hline Ciprofloxacin & DD & 87 (98.9) & $1(1.1)$ & $0(0)$ & $0(0)$ \\
\hline Minocycline & DD & 82 (93.2) & $6(6.8)$ & $0(0)$ & $0(0)$ \\
\hline
\end{tabular}

Abbreviations: $\mathrm{CA}$, categorical agreement; $\mathrm{mE}$, minor error; ME, major error; VME, very major error; DD, disk diffusion method.

\section{KSCM-3 패널과 표준검사법에 의한 항균제 감수성 결과 비교}

포도당 비발효 그람음성균의 $\mathrm{KSCM}-3$ 패널과 디스크확산법에 의한 항균제 감수성 결과의 항균제별 분포를 Supplementary Fig. 5,6 과 Table 3 에 정리하였다. P. aeruginos $a$ 를 검사한 항균제인 piperacillin, piperacillin-tazobactam, ceftazidime, cefepime, imipenem, meropenem, amikacin, gentamicin, tobramycin 및 ciprofloxacin에서 CA의 비율이 $90 \%$ (91.8\%-100\%) 이상의 우수한 결과 를 보였다. $\mathrm{ME}$ 의 비율은 ceftazidime과 ciprofloxacin에서 $0.9 \%$ (1/110)였으며, 그 이외의 항균제에서는 관찰되지 않았다. 또한, cefepime과 amikacin에서 1건의 $\mathrm{VME}$ 를 확인하였으나 그 비율이 모두 $1.5 \%$ 미만이었다. A. baumannii에서 디스크확산법으로 검사 한 항균제인 piperacillin, ampicillin-sulbactam, ceftazidime, cefepime, imipenem, meropenem, amikacin, gentamicin, tobramycin, ciprofloxacin 및 minocycline에서 CA의 비율이 90\% (95.5\%-100\%) 이상으로 높은 일치율을 나타내었다. $\mathrm{ME}$ 는 모든 항균제에서 관찰 되지 않았고, $\mathrm{VME}$ 는 piperacillin에서 1건이 확인되었다.

\section{4. 그람음성균에서 KSCM 패널과 표준검사법에 의한 colistin 항균제 감수성 결과 비교}

그람음성균의 $\mathrm{KSCM}-2$ 및 $\mathrm{KSCM}-3$ 패널과 표준검사법에 의
한 colistin 항균제 감수성 결과의 균주별 분포를 Fig. 1 및 Table 4에 정리하였다. $m c r-1$ 생성 colistin 내성 균주 18 주와 $m c r-1$ 비생성 colistin 내성 균주 73주 및 colistin 감수성 균주 34주를 검사한 결과, $m c r-1$ 생성 균주는 모두 정확하게 내성을 검출한 반면, $m c r-1$ 비생성 colistin 내성 균주에서 6건의 $\mathrm{ME}$ 가 발생하였다. Colistin에 대한 전체 $\mathrm{CA}$ 의 비율은 $94.4 \%$ (118/125)로 높은 일치율을 보였고, $\mathrm{ME}$ 의 비율은 $4.8 \%(\mathrm{n}=6)$, $\mathrm{VME}$ 의 비율은 $0.8 \%(\mathrm{n}=1)$ 였다.

\section{DISCUSSION}

항균제 내성균의 확산은 공중 보건을 위협하는 심각한 문제 이다[16]. 정확하고 신속한 항균제 감수성 검사의 보고는 적절 한 항균 치료를 위해 매우 중요한 요소이다. 또한 새로이 출현 하는 내성의 빠른 검출이 매우 중요하다. 본 연구자들은 국내 실정에 맞는 3 가지 항균제 감수성 시험 패널(KSCM-1, KSCM-2, $\mathrm{KSCM}-3$ )을 고안하였고, 그 검사능을 평가하였다.

$\mathrm{KSCM}-1$ 에서는 MRSA의 검출을 위해 oxacillin 및 cefoxitin 을 포함시켰다. MRSA는 임상영역에서 가장 중요한 그람 양성 다제내성균 중 하나이다. MRSA의 검출을 위한 항균제 감수성 


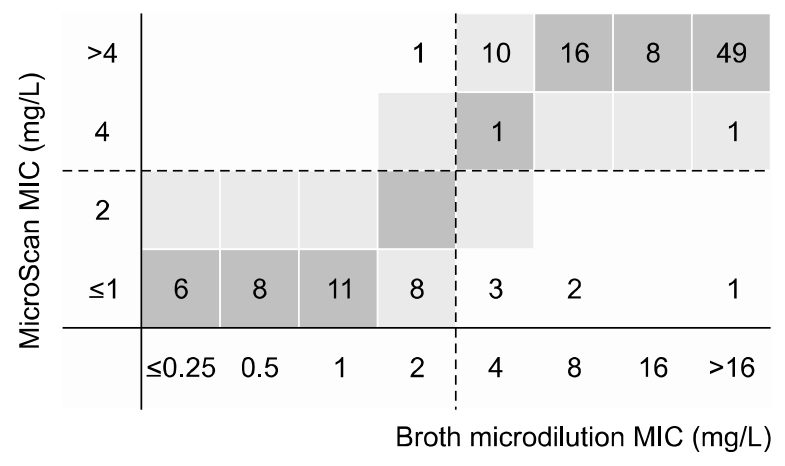

Fig. 1. Susceptibility testing results for colistin in Gram-negative bacilli. The MICs for colistin in clinical isolates of Gram-negative bacilli obtained by the MicroScan were compared with the MICs by broth microdilution method. Abbreviation: MIC, minimal inhibitory concentration.

Table 4. Susceptibility testing results for colistin by MicroScan and broth microdilution method in Gram-negative bacilli

\begin{tabular}{lccll}
\hline \multicolumn{1}{c}{ Strains } & CA & EA & ME & VME \\
\hline Total & $118(94.4)$ & $118(94.4)$ & $6(4.8)$ & $1(0.8)$ \\
Colistin R, mcr-1-producer & $18(100)$ & $18(100)$ & $0(0)$ & $0(0)$ \\
Escherichia coli & $12(100)$ & $12(100)$ & $0(0)$ & $0(0)$ \\
Klebsiella pneumoniae & $4(100)$ & $4(100)$ & $0(0)$ & $0(0)$ \\
Acinetobacter species & $1(100)$ & $1(100)$ & $0(0)$ & $0(0)$ \\
Enterobacter aerogenes & $1(100)$ & $1(100)$ & $0(0)$ & $0(0)$ \\
Colistin R, mcr-1-non-producer & $67(91.8)$ & $67(91.8)$ & $0(0)$ & $6(8.2)$ \\
Escherichia coli & $14(82.4)$ & $14(82.4)$ & $0(0)$ & $3(17.6)$ \\
Klebsiella pneumoniae & $17(85.0)$ & $17(85.0)$ & $0(0)$ & $3(15.0)$ \\
Acinetobacter species & $36(100)$ & $36(100)$ & $0(0)$ & $0(0)$ \\
Colistin S & $33(97.1)$ & $33(97.1)$ & $1(0.9)$ & $0(0)$ \\
Escherichia coli & $22(95.7)$ & $22(95.7)$ & $1(4.3)$ & $0(0)$ \\
Klebsiella pneumoniae & $11(100)$ & $11(100)$ & $0(0)$ & $0(0)$ \\
\hline
\end{tabular}

Abbreviations: CA, categorical agreement; EA, essential agreement; ME, major error; R, resistant; S, susceptible; VME, very major error.

시험에는 oxacillin 또는 cefoxitin이 이용되는데, 그 중 cefoxitin 의 최소억제농도를 기준으로 MRSA를 검출하는 것이 oxacillin 의 최소억제농도를 기준으로 하는 것보다 그 검출능이 우수하 다고 알려져있다[17]. Fernandes 등의 연구(2005)에 따르면, 다 제내성 MRSA의 경우 oxacillin과 cefoxitin의 최소억제농도가 모두 높았으나, 비다제내성 MRSA의 경우에는 oxacillin의 최 소억제농도가 낮은 경우가 적지 않음을 보고한 바 있다[18]. 추 가적으로 $\mathrm{KSCM}-1$ 패널에는 MRSA의 치료제로 최근 출시된 ceftaroline을 포함시켰다. Ceftaroline은 항-MRSA cephalosporin의 한 종류로 PBP2A에 결합하는 베타락탐 항균제다[19]. 국 내에는 아직 출시되지 않았지만, 이미 내성이 보고되고 있어 그 중요성이 크다고 판단된다[20].

$\mathrm{KSCM}-2$ 과 $\mathrm{KSCM}-3$ 패널은 $\mathrm{CRE}, \mathrm{CPE}, \mathrm{CRPA}, \mathrm{CRAB}$ 등의 증가로 인해 최근 임상영역에서 사용이 증가하고 있는 colistin 을 포함하였다. Colistin에 대한 항균제 감수성 시험은 미량액 체배지희석법으로 하는 것을 표준법으로 권고하고 있으며, 디 스크확산법, E-test 및 다수의 자동화 장비에서 오류율이 높음
이 보고된 바 있다[21]. 또한, 국내에 출시되어 있는 다수의 감 수성 시험 패널은 ciprofloxacin의 최소억제농도 측정 범위가 Salmonella 균종의 clinical breakpoint를 반영하지 못하였다. 따 라서, 본 패널에는 $0.06-0.5 \mathrm{mg} / \mathrm{L}$ 범위의 ciprofloxacin 농도를 추가하였다. 또한 국내에서는 아직 출시되지 않았지만, $\mathrm{CPE}$ 의 치료를 위해 출시된 신약인 ceftazidime-avibactam과 ceftolozane-tazobactam을 패널에 추가하였다.

본 연구는 다수의 임상분리균주를 대상으로 AST 패널의 항 균제 감수성 검사의 분석능을 평가하였다. 국내의 8 개 병원에 서 수집된 균주를 이용하였으며, 임상에서 분리비율이 높은 균 종, 즉 E. coli, K. pneumonia, A. baumannii, P. aeruginosa, S. aureus, E. faecium, E. faecalis, Salmonella 등을 연구에 포함시 켰다. 뿐만 아니라, 국내 항균제 내성률에 기초하여 균주를 선 정하여 실제 임상미생물 검사실에서 발생가능한 오차를 반영 하도록 하였다. Carbapenem과 colistin과 같이 내성이 드문 경 우에는 추가로 균주를 포함시켜 검사능을 평가하였다.

$\mathrm{KSCM}-1$ 패널의 경우, S. aureus에서 CA의 비율이 $95.5 \%$ 이 
상으로 우수한 결과를 보였고, $\mathrm{ME}$ 는 고농도 mupirocin 내성 검 출에서 $4 \%$ 로 다소 높았다. 본 연구에서 사용된 고농도 mupirocin내성 검출법은 CLSI의 권고에 따라 디스크확산법을 이용 하였으나, 미량액체배지희석법의 정확도가 더 높은 것으로 알 려져 있어, 디스크확산법의 오류일 가능성을 배제할 수 없을 것으로 판단된다[22]. 그 외의 항균제의 $\mathrm{ME}$ 비율과 $\mathrm{VME}$ 비율 은 관찰되지 않아 우수한 결과라 판단된다. E-test와 비교한 항 균제의 결과에서도 높은 일치율을 보여 좋은 분석능을 보여 주 었다. Enterococcous 균종 CA의 비율은 고농도 aminoglycoside 항균제와 ciprofloxacin을 제외한 모든 항균제에서 $90 \%$ 이상이 었으며, $\mathrm{ME}$ 와 $\mathrm{VME}$ 의 비율도 모두 $1 \%$ 이하로 우수한 결과를 보여주었다.

그람음성 Enterobacteriaceae 감수성 시험 패널인 $\mathrm{KSCM}-2$ 의 경우 디스크확산법과 비교한 $\mathrm{CA}$ 의 비율이 모두 $90 \%$ 이상 의 우수한 결과가 나왔으며, trimethoprime-sulfamethoxazole에 서 $\mathrm{ME}$ 와 $\mathrm{VME}$ 의 비율이 각각 $2.9 \%, 0.5 \%$ 로 다소 높았으나, 허 용범위 이내였다[15]. 한천희석법과 비교한 결과 또한 $\mathrm{CA}, \mathrm{EA}$, $\mathrm{ME}$ 및 $\mathrm{VME}$ 의 비율이 모두 CLSI가 권고하는 기준에 부합하 여 높은 일치율을 보인 것으로 판단된다. Salmonella는 미량액 체배지희석법과 비교한 결과, 저농도 ciprofloxacin을 포함한 모 든 항균제에서 $\mathrm{CA}$ 와 $\mathrm{EA}$ 의 비율이 모두 $90 \%$ 이상이었으며 $\mathrm{ME}$ 와 $\mathrm{VME}$ 의 비율도 기준에 부합하였다. $\mathrm{KSCM}-3$ 패널을 이 용한 검사능 평가에는 P. aerugionosa와 A. baumannii가 포함 되었다. P. aeruginosa에서는 CA의 비율이 $91.8 \%$ 에서 $100 \%$ 로 우수한 결과를 보였다. Ceftazidime과 ciprofloxacin에서 각각 1 건의 $\mathrm{ME}$ 와 cefepime과 amikacin에서 각각 1 건의 $\mathrm{VME}$ 만이 관 찰되었다. A. baumannii 는 CA의 비율이 $95.5 \%$ 에서 $100 \%$ 로 가 장 높은 일치율을 보여주었고, $\mathrm{ME}$ 는 관찰되지 않았고, $\mathrm{VME}$ 는 piperacillin에서 1건만이 확인되어 우수한 결과를 보여주었다.

본 연구에서 $\mathrm{KSCM}$ 패널 결과 평가에 이용된 표준법으로 디 스크 확산법이 사용되었다는 것은 중요한 한계점이다. 고찰에 서 언급된 바와 같이 디스크 확산법의 결과와 $\mathrm{KSCM}$ 패널의 결과가 차이를 보인 경우, 디스크 확산법 결과의 오류 가능성 을 배제할 수 없었다. 다만, 디스크 확산법은 희석법과 비교하 였을 때 그 정확성이 인정되며, 많은 수의 항균제에 대한 감수 성 시험패널의 평가에 널리 이용된다[9,23]. 또한, colistin과 고 농도 aminoglycoside 내성 판정 등과 같이 디스크 확산법의 정 확성이 입증되지 않은 경우에 대해서는 한천희석법 및 미량액 체배지확산법을 사용하였다.

결론적으로 새로이 구성한 MicroScan (Beckman Coulter)의 $\mathrm{KSCM}$ 패널은 최신 항균제 감수성 시험 가이드라인에 맞춘 패 널로서 새로운 항균제를 폭넓게 포함하고 있으며, 임상의의 요 구에 부합하는 시험결과를 제공할 수 있을 것으로 생각한다. 또한, 디스크확산법, 한천희석법, E-test, 미량액체배지희석법과 비교하였을 때, 우수한 결과를 보여주어 임상미생물 검사실에
서 정확도 높은 검사 결과를 보고하는데 도움을 줄 것으로 생 각한다.

\section{REFERENCES}

1. Stefani S, Chung DR, Lindsay JA, Friedrich AW, Kearns AM, Westh H, et al. Meticillin-resistant Staphylococcus aureus (MRSA): global epidemiology and harmonisation of typing methods. Int $\mathrm{J}$ Antimicrob Agents 2012;39:273-82.

2. Cheong HJ, Song JY, Eom JS, Kim WJ, Choi SJ, Choi JH, et al. Colonization rate, risk factor for acquisition and genetic diversity of vancomycin-resistant enterococci (VRE) isolated from rectal culture of patients in intensive care units from ten large hospitals in Korea. Korean J Infect Dis 2002;34:276-84.

3. Kim B, Kim J, Seo MR, Wie SH, Cho YK, Lim SK, et al. Clinical characteristics of community-acquired acute pyelonephritis caused by ESBL-producing pathogens in South Korea. Infection 2013;41:603-12.

4. Gupta N, Limbago BM, Patel JB, Kallen AJ. Carbapenem-resistant Enterobacteriaceae: epidemiology and prevention. Clin Infect Dis 2011;53:60-7.

5. Lee JY and Ko KS. OprD mutations and inactivation, expression of efflux pumps and AmpC, and metallo- $\beta$-lactamases in carbapenem-resistant Pseudomonas aeruginosa isolates from South Korea. Int J Antimicrob Agents 2012;40:168-72.

6. Perez F, Hujer AM, Hujer KM, Decker BK, Rather PN, Bonomo RA. Global challenge of multidrug-resistant Acinetobacter baumannii. Antimicrob Agents Chemother 2007;51:3471-84.

7. Kim D, Ahn JY, Lee CH, Jang SJ, Lee H, Yong D, et al. Increasing resistance to extended-spectrum cephalosporins, fluoroquinolone, and carbapenem in gram-negative bacilli and the emergence of carbapenem non-susceptibility in Klebsiella pneumoniae: analysis of Korean Antimicrobial Resistance Monitoring System (KARMS) data from 2013 to 2015. Ann Lab Med 2017;37:231-9.

8. Magiorakos AP, Srinivasan A, Carey RB, Carmeli Y, Falagas ME, Giske CG, et al. Multidrug-resistant, extensively drug-resistant and pandrug-resistant bacteria: an international expert proposal for interim standard definitions for acquired resistance. Clin Microbiol Infect 2012;18:268-81.

9. CLSI. Performance standards for antimicrobial susceptibility testing. CLSI document M100. Wayne, PA: Clinical and Laboratory Standards Institute; 2018.

10. European Committee on Antimicrobial Susceptibility Testing. Breakpoint tables for interpretation of MICs and zone diameters. Version 8.0. http://www.eucast.org/ast_of_bacteria/previous_versions_ of_documents/ [Online] (last visited on 31 January 2018).

11. Yoon YK, Kim JY, Park DW, Sohn JW, Kim MJ. Predictors of persistent methicillin-resistant Staphylococcus aureus bacteraemia in patients treated with vancomycin. J Antimicrob Chemother 2010;65:1015-8.

12. Choi HG, Park KH, Park SN, Jun BC, Lee DH, Yeo SW. The appropriate medical management of methicillin-resistant Staphylococcus aureus in chronic suppurative otitis media. Acta Otolaryngol 2010;130:42-6.

13. Steers E, Foltz EL, Graves BS. An inocula replicating apparatus for routine testing of bacterial susceptibility to antibiotics. Antibiot Chemother (Northfield) 1959;9:307-11.

14. European Committee on Antimicrobial Susceptibility Testing. Recommendations for MIC determination of colistin (polymyxin E) as recommended by the joint CLSI-EUCAST Polymyxin 
Breakpoints Working Group. http://www.eucast.org/ast_of bacteria/ guidance_documents/ [Online] (last visited on 31 March 2016).

15. CLSI. Verification of commercial microbial identification and antimicrobial susceptibility testing systems. CLSI document M52. Wayne, PA: Clinical and Laboratory Standards Institute; 2015.

16. Levy SB. Antibiotic and antiseptic resistance: impact on public health. Pediatr Infect Dis J 2000;19(10 Suppl):S120-2.

17. Felten A, Grandry B, Lagrange PH, Casin I. Evaluation of three techniques for detection of low-level methicillin-resistant Staphylococcus aureus (MRSA): a disk diffusion method with cefoxitin and moxalactam, the Vitek 2 system, and the MRSA-screen latex agglutination test. J Clin Microbiol 2002;40:2766-71.

18. Fernandes CJ, Fernandes LA, Collignon P; Australian Group on Antimicrobial Resistance. Cefoxitin resistance as a surrogate marker for the detection of methicillin-resistant Staphylococcus aureus. J Antimicrob Chemother 2005;55:506-10.

19. Villegas-Estrada A, Lee M, Hesek D, Vakulenko SB, Mobashery S. Co-opting the cell wall in fighting methicillin-resistant Staphylococcus aureus: potent inhibition of PBP 2a by two anti-MRSA beta-lactam antibiotics. J Am Chem Soc 2008;130:9212-3.

20. Lee H, Yoon EJ, Kim D, Kim JW, Lee KJ, Kim HS, et al. Ceftaroline resistance by clone-specific polymorphism in penicillinbinding protein 2a of methicillin-resistant Staphylococcus aureus. Antimicrob Agents Chemother 2018;62:e00485-18.

21. Lo-Ten-Foe JR, de Smet AM, Diederen BM, Kluytmans JA, van Keulen PH. Comparative evaluation of the VITEK 2, disk diffusion, Etest, broth microdilution, and agar dilution susceptibility testing methods for colistin in clinical isolates, including heteroresistant Enterobacter cloacae and Acinetobacter baumannii strains. Antimicrob Agents Chemother 2007;51:3726-30.

22. Malaviolle X, Nonhoff C, Denis O, Rottiers S, Struelens MJ. Evaluation of disc diffusion methods and Vitek 2 automated system for testing susceptibility to mupirocin in Staphylococcus aureus. J Antimicrob Chemother 2008;62:1018-23.

23. Donay JL, Mathieu D, Fernandes P, Prégermain C, Bruel P, Wargnier A, et al. Evaluation of the automated Phoenix system for potential routine use in the clinical microbiology laboratory. J Clin Microbiol 2004;42:1542-6. 
$=$ 국문초록 $=$

\section{MicroScan의 한국형 항생제 감수성 시험 패널인 KSCM 패널에 대한 다기관 임상 분리 균주를 이용한 분석능 평가}

${ }^{1}$ 연세대학교 의과대학 진단검사의학교실 및 세균내성연구소, ${ }^{2}$ 상지대학교 보건과학대학 일반대학원 임상병리학과 강다영 ${ }^{1,2}$, 홍준성 $^{1}$, 박별이 $^{1,2}$, 장인호 $^{2}$, 김도균 $^{1}$, 이혁민 $^{1}$, 정석훈 $^{1}$

배경: 항균제 내성은 공중보건에 계속적인 위협이 되고 있다. 임상미생물 검사실에서의 빠른 항생제 감수성 시험을 통한 내성의 검출은 감염관리 및 환자 치료에 중요하며, 이를 위한 적절한 자동화 검사 장비 및 항생제 감수성시험 패널은 필수적인 요소이다. 본 연구에서 MicroScan 장비(Beckman Coulter, USA)의 새로운 항생제 감수성 시험패널을 디자인하였 으며, 그 검사능을 많은 임상분리 균주를 이용하여 평가하였다.

방법: 총 3종류의 항생제 감수성 패널(KSCM-1, KSCM-2, KSCM-3)을 구성하였다. 1,027주의 그람음성 세균(Escherichia coli, Klebsiella pneumoniae, Klebsiella oxytoca, Pseudomonas aeruginosa, Acinetobacter baumannii, Enterobacter spp.)과 298주 의 그람양성 세균(Staphylococcus aureus, Enterococcus faecium, Enterococcus faecalis)을 포함한 총 1,325주의 임상분리 균 주를 이용하여 새로이 구성된 패널의 검사능을 평가하였다. MicroScan KSCM 패널의 결과는 디스크확산법, Etest, 한천희 석법, 미량액체희석법의 결과와 비교하였다.

결과: 그람 양성알균을 대상으로 한 KSCM-1 패널을 구성하였다. KSCM-1 패널의 결과를 표준검사법과 비교하였을 때, S. aureus 에서 categorical agreement (CA) 비율이 $90 \%$ 이상이었고, major error (ME)는 고농도 mupirocin 내성에서의 4건을 제외하고는 관찰되지 않았다. Very major error (VME)는 모든 항생제에서 관찰되지 않았다. Enterococci에서도 CA 비율은 $90 \%$ 이상, $\mathrm{ME}$ 비율은 3\% 미만이었다. $\mathrm{VME}$ 는 ampicillin, tetracycline과 quinupristin-dalfopristin에서 각각 1건을 확인하였 고, 나머지 항생제에서는 관찰되지 않았다. 장내세균속 검사용 패널(KSCM-2)의 검사능 평가에서, 검사한 모든 항생제에 대하여 $\mathrm{CA}$ 비율은 $90 \%$ 이상, $\mathrm{ME}$ 비율은 $3 \%$ 미만이었으며 $\mathrm{VME}$ 의 비율은 $1.5 \%$ 이하였다. 포도당 비발효 그람음성막대 균의 항생제 감수성 시험 패널(KSCM-3)의 검사능 평가에서도, P. aeruginosa는 CA 비율은 $90 \%$ 이상이었으며, ME는 ceftazidime과 ciprofloxacin에서 각각 한건씩 관찰되었으며, 그 이외의 항생제에서는 관찰되지 않았다. $\mathrm{VME}$ 의 비율은 검사 한 모든 항균제에서 $1.5 \%$ 미만이었다. A. baumannii에서는 CA 비율 $90 \%$ 이상이었으며, VME는 piperacillin에서 1 건이 확인되었다.

결론: 새로이 구성한 $\mathrm{KSCM}$ 패널의 결과를 표준검사법의 결과와 비교하였을 때, 높은 일치율을 보여주어 임상미생물 검사실에 적용 가능할 것으로 생각한다. [Ann Clin Microbiol 2019;22:61-70]

교신저자 : 김도균, 06273 , 서울시 강남구 언주로 211

연세대학교 의과대학 강남세브란스병원 진단검사의학과 및 세균내성연구소

Tel: 02-2019-2776, Fax: 02-2057-8926

E-mail: kyunsky@yuhs.ac 